\title{
Fauna do solo associada a diferentes sistemas de cultivo
}

\author{
Soil fauna associated with different cultivation systems \\ Fauna del suelo asociada a diferentes sistemas de cultivo
}

\section{Resumo}

A fauna edáfica tem sido amplamente utilizada como bioindicadora da qualidade do solo em agroecossistemas por responder rapidamente às alterações decorrentes do uso e manejo em sistemas agrícolas. Objetivou-se neste estudo avaliar a fauna do solo associado a sistemas de cultivo convencionais e sustentáveis. Os sistemas estudados foram cana convencional, cana orgânica, milho orgânico consorciado com guandu-anão, milho orgânico em monocultivo, sistema agroflorestal, solo em pousio e vegetação nativa. Foram instaladas, em cada área, quatro armadilhas de queda ("pitfall") para captura dos organismos da fauna do solo, ao longo de um transecto, equidistantes de $5 \mathrm{~m}$, totalizando 28 armadilhas. Coletou-se um total de 1330 indivíduos, distribuídos em 50 táxons, sendo Formicidae, Collembola e Diptera: Phoridae os predominantes. Os indivíduos pertencentes ao grupo trófico funcional predadores foram os mais representativos na maioria das áreas estudadas. Os sistemas pousio, agrofloresta, cana convencional e vegetação nativa mostraram maior abundância de indivíduos da fauna do solo. A riqueza de grupos foi maior nos sistemas com milho orgânico em monocultivo, consorciado com guandu-anão e pousio, com as duas áreas de milho apresentando maior uniformidade na distribuição dos grupos da fauna do solo. Estes resultados podem auxiliar na classificação de alguns grupos de invertebrados como bioindicadores de qualidade do solo em agroecossistemas. Palavras-chave: Bioindicadores; Diversidade; Índices ecológicos; Qualidade do solo.

\begin{abstract}
The edaphic fauna has been widely used as a bioindicator of soil quality in agroecosystems because it responds quickly to changes resulting from the use and management of agricultural systems. The objective of this study was to evaluate soil fauna associated with conventional and sustainable cultivation systems. The studied systems were conventional cane, organic cane, organic corn intercropped with pigeon pea dwarf, organic corn in monoculture, agroforestry system, fallow soil, and native vegetation. Four pitfall traps were installed in each area to capture soil fauna organisms, along a transect, equidistant to $5 \mathrm{~m}$, totaling 28 traps. A total of 1330 individuals were collected, distributed in 50 taxa, with Formicidae, Collembola, and Diptera: Phoridae the predominant ones. Individuals belonging to the predatory functional trophic group were the most representative in most of the areas studied. The fallow, agroforestry, conventional cane, and native vegetation systems showed a greater abundance of soil fauna individuals. The richness of groups was higher in systems with organic maize in monoculture, intercropped with pigeon pea and fallow, with the two maize areas showing greater uniformity in the distribution of soil fauna groups. These results can assist in the classification of some groups of invertebrates as bioindicators of soil quality in agroecosystems.
\end{abstract}

Keywords: Bioindicators; Diversity; Ecological indexes; Soil Quality. 


\begin{abstract}
Resumen
La fauna edáfica ha sido ampliamente utilizada como bioindicador de la calidad del suelo en agroecosistemas porque responde rápidamente a los cambios resultantes del uso y manejo de los sistemas agrícolas. El objetivo de este estudio fue evaluar la fauna del suelo asociada a sistemas de cultivo convencionales y sostenibles. Los sistemas estudiados fueron caña convencional, caña orgánica, maíz orgánico intercalado con frijol guandú-anão, maíz orgánico en monocultivo, sistema agroforestal, barbecho y vegetación nativa. Se instalaron cuatro trampas de caída en cada área para capturar organismos de fauna del suelo, a lo largo de un transecto, equidistante a $5 \mathrm{~m}$, totalizando 28 trampas. Se recolectaron un total de 1330 individuos, distribuidos en 50 taxones, predominando Formicidae, Collembola y Diptera: Phoridae. Los individuos pertenecientes al grupo trófico funcional depredador fueron los más representativos en la mayoría de las áreas estudiadas. Los sistemas de barbecho, agroforestería, caña convencional y vegetación nativa mostraron mayor abundancia de individuos de fauna del suelo. La riqueza de grupos fue mayor en sistemas con maíz orgánico en monocultivo, intercalado con frijol gunadúanão y barbecho, mostrando las dos áreas de maíz una mayor uniformidad en la distribución de los grupos de fauna del suelo. Estos resultados pueden ayudar en la clasificación de algunos grupos de invertebrados como bioindicadores de la calidad del suelo en los agroecosistemas.
\end{abstract}

Palabras clave: Bioindicadores; Diversidad; Índices ecológicos; Calidad del suelo.

\title{
1. Introdução
}

A intensificação e expansão das fronteiras agrícolas tem impulsionado o declínio da biodiversidade global. Por meio da conversão do uso da terra, mudanças nas práticas agrícolas convencionais, uso de pesticidas e fertilizantes sintéticos, adoção de sistemas de monoculturas, mecanização, entre outras práticas utilizadas para aumentar a produção agrícola levaram a diminuição gradativa da diversidade biológica nos diferentes sistemas naturais e artificiais (Emmerson et al., 2016; Green et al., 2005). Essas ações têm culminado, em uma grande dependência de insumos, técnicas e práticas comerciais e, consequentemente, elevando o custo econômico e ambiental.

Os futuros sistemas de produção enfrentarão a tarefa desafiadora de evoluir de forma que garantam produtividade, diminuam a dependência de insumos químicos e recursos não renováveis e mantenham ou melhorem a prestação de serviços ecossistêmicos (Wezel et al., 2015). Integrar a diversidade biológica e os princípios ecológicos na agronomia e aplicá-los à agricultura é uma estratégia para alcançar a intensificação agroecológica desejada (Bommarco et al., 2013; Wezel et al., 2015) e conservar as funções do ecossistema (Chabert \& Sarthou, 2020).

Essa forma de agricultura inclui, principalmente, a diversificação ecológica, espacial e temporal como o núcleo dos sistemas de gerenciamento de culturas (Duru et al., 2015; Kremen \& Miles, 2012).

A agricultura com premissas sustentáveis vem se tornando uma prática promissora global. Em 2018, aproximadamente 2,8 milhões de agricultores administram suas propriedades adotando práticas de produção orgânica (Willer \& Lernoud, 2019). As vendas globais de alimentos e bebidas orgânicos atingiram 95 bilhões de euros neste mesmo ano, de acordo com a Ecovia Intelligence (2020). Isso mostra que os sistemas de cultivo sustentáveis vêm ganhando cada vez mais espaço no panorama mundial nos últimos anos.

O estudo de sistemas sustentáveis está cada vez mais em evidencia na literatura científica e as respostas desse tipo de agricultura podem variar de acordo com condições ambientais e climáticas, além do tipo de estratégia usada. Conforme enfatizado por Bender et al. (2016), para se beneficiar totalmente dos processos naturais, os sistemas sustentáveis precisam integrar a engenharia ecológica do solo, o que requer alto entendimento dos processos edáficos.

Sabe-se que os parâmetros biológicos tendem a ser mais sensíveis e relacionar mais rapidamente que os parâmetros físicos e químicos, e, por isso, vem sendo usados frequentemente para indicar a qualidade do solo (Brussaard et al., 2007). Segundo Assad et al. (1997), o biofuncionamento do solo constitui o conjunto de funções edáficas que, interagindo com fatores ambientais, são estreitamente dependentes de regulações biológicas. Desta forma, alguns invertebrados possuem papel de destaque no funcionamento do solo, exercendo funções específicas que vão depender da sua morfologia, mobilidade, cadeia trófica, interação com outros organismos e da posição que ocupam no espaço (Feigl et al., 2019; Melo et al., 2009; Hopkin \& Read, 1992; Amazonas et al., 2018).

Os organismos da fauna edáfica podem modificar o solo e o ambiente onde vivem por meio de diversos mecanismos, como movimentação de material sobre o solo e dentro dele; enterro ativo de restos vegetais depositados na superfície; movimentação de 
quantidades variáveis de partículas de diferentes tamanhos; construção de montículos, cavidades, galerias e ninhos; ingestão, digestão e excreção de restos orgânicos e de partículas minerais; participação nos ciclos biogeoquímicos tornando disponíveis vários elementos; e, contribuição para o desenvolvimento estrutural do solo (Assad, 1997).

Diante do exposto, o objetivo do presente estudo foi avaliar a fauna edáfica associado a sistemas de cultivo sustentáveis e convencionais. Nossa hipótese é que os sistemas de cultivo sustentáveis, como sistemas orgânicos e agroecológicos, apresentam maior diversidade taxonômica da fauna no solo e, consequentemente, maior similaridade ao ambiente natural.

\section{Metodologia}

\section{Caracterização da área de estudo}

O estudo foi conduzido na área experimental do Centro de Ciências Agrárias da Universidade Federal de São Carlos, Araras-

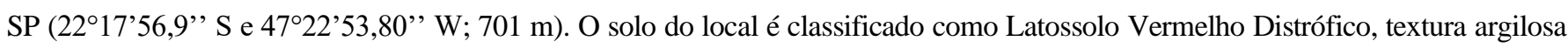
(Embrapa, 2006). O clima da região é do tipo Cwa, mesotérmico, segundo a classificação de Köppen e Geiger (1928), caracterizado por verões quentes e úmidos e invernos secos. Os dados climáticos (intervalos de 10/11 dias) de janeiro a março de 2015 estão sumarizados na Tabela 1.

Tabela 1. Dados de precipitação pluviométrica (mm) e temperaturas ('C) mínima (Mín), máxima (Máx) e média observados durante os meses de janeiro a março de 2015.

\begin{tabular}{|c|c|c|c|c|c|c|}
\hline \multirow[b]{2}{*}{ Mês } & \multirow[b]{2}{*}{ Intervalos (dias) } & \multicolumn{2}{|c|}{ Precipitação (mm) } & \multicolumn{3}{|c|}{ Temperatura $\left({ }^{\circ} \mathrm{C}\right)$} \\
\hline & & $\begin{array}{c}\text { Por } \\
\text { intervalo }\end{array}$ & $\begin{array}{c}\text { Total } \\
\text { mensal }\end{array}$ & Mín & Máx & Média \\
\hline \multirow{3}{*}{ Janeiro } & 01 a 10 & 25,8 & \multirow{3}{*}{127,8} & 19,9 & 32,8 & 26,4 \\
\hline & 11 a 20 & 55,0 & & 20,7 & 36,0 & 28,4 \\
\hline & 21 a 31 & 50,0 & & 19,2 & 31,1 & 25,2 \\
\hline \multirow{3}{*}{ Fevereiro } & 01 a 10 & 37,8 & \multirow{3}{*}{212,6} & 17,7 & 30,1 & 23,9 \\
\hline & 11 a 20 & 124,0 & & 19,6 & 30,4 & 25,0 \\
\hline & 21 a 28 & 50,8 & & 18,4 & 31,9 & 25,1 \\
\hline \multirow{3}{*}{ Março } & 01 a $10 *$ & 49,0 & \multirow{3}{*}{173,4} & 18,4 & 29,7 & 24,1 \\
\hline & 11 a 20 & 50,2 & & 18,4 & 26,8 & 22,6 \\
\hline & 21 a 31 & 74,2 & & 17,5 & 29,6 & 23,5 \\
\hline
\end{tabular}

DRNPA/CCA/UFSCar, Araras, SP. *Período de instalação das armadilhas. Fonte: Estação Meteorológica Automática (E.M.A.),

\section{Delineamento experimental e caracterização do experimento}

O delineamento experimental adotado foi blocos casualizados. Em cada área foram instaladas quatro armadilhas de queda ("pitfall") ao longo de um transecto, equidistantes de $5 \mathrm{~m}$, totalizando 28 armadilhas. As áreas possuíam diferentes históricos e coberturas do solo (sistemas de cultivo sustentáveis e convencionais) e pousio: i) Cana-de-açúcar convencional (CC); ii) Cana-deaçúcar orgânico (CO); iii) Milho orgânico consorciado com guandu-anão (MG); iv) Milho orgânico em monocultivo (MM); v) Sistema agroflorestal (SAF); vi) Pousio (P); vii) Vegetação nativa (VN). Cada área selecionada foi delimitada em 30 x 20 m (600 m²).

i = Cana-de-açúcar convencional (CC): a variedade utilizada foi a RB855453, implantada em 2014, com espaçamento de 1,4 m na entrelinha e 24 gemas por metro linear. Foram realizadas três adubações na área: 400 kg da fórmula 6-30-20 (N-P-K) no sulco de plantio; $270 \mathrm{~kg}$ de 19-00-24 (N-P-K), (em cobertura); e $500 \mathrm{~kg}$ de 20-00-20 (N-P-K), no cultivo da cana soca. Para o manejo de plantas espontâneas foram utilizados os herbicidas: sulfentrazona (ingrediente ativo) no pré-plantio; diurom + hexazinona na pré e pósemergência (45 dias após a semeadura) e metribuzim na pré e pós-emergência (cana soca). Para o controle de pragas foi aplicado o 
ingrediente ativo fipronil, no sulco de plantio. Máquinas e implementos agrícolas foram utilizados no preparo do solo e aplicação de defensivos.

ii = Cana-de-açúcar orgânica (CO): a variedade utilizada foi a RB867515, implantada em 2013, com espaçamento de 1,4 m na entrelinha e 24 gemas por metro linear. Para a adubação utilizou-se $9,8 \mathrm{t} \mathrm{ha}^{-1}$, em peso seco e com respectiva correção de umidade, do composto Visafértil Orgânico ${ }^{\circledR}$, distribuído na linha de semeadura, por ocasião do plantio. Para o controle das plantas espontâneas foi realizada a capina da área no estádio inicial de crescimento da cultura. Não foram utilizados máquinas e implementos na área.

iii = Milho orgânico consorciado com guandu-anão (MG): a variedade utilizada foi a AL Avaré. A área foi formada por linhas de milho espaçadas entre si 0,9 m, com seis sementes por metro linear. O guandu-anão foi semeado na densidade de 10 sementes por metro, sendo uma linha da leguminosa na linha do milho e duas linhas nas entrelinhas. O controle de plantas espontâneas por meio de capina manual foi realizado em dois períodos: aos 20 dias e 48 dias após a emergência do milho. Para a adubação foram aplicados $800 \mathrm{~kg}$ do composto Visafértil Orgânico ${ }^{\circledR}$ seco, equivalente a $13 \mathrm{t} \mathrm{ha}^{-1}$, distribuído de forma homogênea sobre o solo, ao lado da linha de semeio do milho. A irrigação por aspersão foi realizada de forma suplementar, sendo acionada somente após o segundo dia sem chuva significativa. Consta o uso de maquinário para o preparo do solo.

iv = Milho orgânico em monocultivo (MM): foi utilizada a variedade AL Avaré. A área foi constituída por linhas de milho espaçadas entre si $0,80 \mathrm{~m}$, com cinco plantas por metro e densidade populacional de 62.500 plantas ha $^{-1}$. Foram aplicados $10 \mathrm{t} \mathrm{ha}^{-1}$, em peso seco e com respectiva correção de umidade, do composto Visafértil Orgânico ${ }^{\circledR}$, distribuído na linha de semeadura, por ocasião do plantio. O controle de plantas espontâneas foi por meio de três capinas manuais. A lagarta-do-cartucho Spodoptera frugiperda (J.E. Smith) (Lepidoptera: Noctuidae) foi controlada com o uso de Bacillus thuringiensis var. kurstaki (Dipel WP ${ }^{\circledR}$ na dose de $500 \mathrm{~g} \mathrm{ha}^{-1}(16,80 \mathrm{~g}$ $\mathrm{ha}^{-1}$ de ingrediente ativo). Foi utilizado maquinário para o preparo do solo.

$\mathbf{v}=$ Sistema agroflorestal (SAF): A área onde foi implantado o SAF se encontrava em pousio por cerca de 10 anos. O sistema foi implantado em 2010, sem a utilização de insumos para adubação, sendo realizada somente uma calagem por cova. As espécies vegetais presente na área são as seguintes Anadenanthera colubrina (Vell.) Brenanangico (angico), Cajanus cajan (L.) Millsp. (feijão guandu), Canavalia ensiformis (L.) DC. (feijão de porco), Capsicum frutescens L. (pimenta Cambuci), Cariniana legalis (Mart.) Kuntze (jequitibá-rosa), Cecropia pachystachya (embaúba), Citrus limonum (L) Burm. f. (limão), Cucurbita moschata Duch. (abóbora), Eugenia uniflora L. (pitanga), Hymenaea courbaril L. (jatobá), Manihot esculenta Crantz (mandioca), Musa spp. (banana), Phaseolus vulgaris L. (feijão), Psidium guajava L. (goiabeira), Schinus terebinthifolius (aroeira), Schizolobium parahyba (guapuruvu), Spondias purpurea L. (seriguela), Tithonia diversifolia (Hemsl.) A. Gray (margaridão) e Zea mays L. (milho).

$\mathbf{v i}=$ Pousio $(\mathrm{P})$ : Área em pousio há 20 meses, com predominância de Desmodium adscendens (Sw.) D.C. (carrapicho). Foi anteriormente cultivada com a cultura da soja (Glicine Max L.) em consórcio com C. cajan, Crotalaria ochroleuca G. Don (crotalária) e Pennisetum americanum (L.) (milheto).

vii = Vegetação nativa (VN): cobertura vegetal de Floresta Estacional Semidecidual, localizado a 500-1000 m das áreas de estudo.

As áreas P e VN foram incluídas no estudo como referencial para a qualidade do solo.

\section{Avaliações}

\section{Umidade do solo}

A umidade do solo foi obtida próxima às armadilhas, por meio de um trado holandês. As coletas foram realizadas na profundidade de 0,0-0,10 m. As amostras foram submetidas ao método termogravimétrico (Claessen, 1997), que consiste em pesar a massa de solo úmido (MU) e em seguida secá-lo em estufa a $105-110{ }^{\circ} \mathrm{C}$ por 24 horas e, após esse período, determinar sua massa 
seca (MS). A umidade foi calculada pela equação: $\mathrm{U}\left(\mathrm{kg} \mathrm{kg}^{-1}\right)=[(\mathrm{Mu}-\mathrm{Ms}) / \mathrm{Mu}]$ x 100. Onde: $\mathrm{U}=$ umidade do solo $\left(\mathrm{kg} \mathrm{kg}^{-1}\right) ; \mathrm{Mu}=$ massa de solo úmido $(\mathrm{g})$; Ms = massa de solo seco em estufa $(\mathrm{g})$.

\section{Caracterização da fauna do solo}

Foram instaladas, no centro de cada área, cinco armadilhas de queda ("pitfall”), ao longo de um transecto, equidistantes $5 \mathrm{~m}$ entre si. As armadilhas foram confeccionadas com recipientes plásticos de 9 x $11 \mathrm{~cm}$ (diâmetro x altura). Cada uma continha $200 \mathrm{~mL}$ de solução conservante de formol a $4 \%$ e cinco gotas de detergente para quebra da tensão superficial da solução. Após sete dias, as armadilhas foram retiradas e os invertebrados armazenados em álcool 70\%. Com o auxílio de um estereoscópio, procedeu-se à triagem e identificação dos organismos em nível de grandes grupos taxonômicos (Classe, Ordem ou Família).

A caracterização da comunidade da fauna foi realizada com base na composição taxonômica (\%); abundância ( $n^{\circ}$ de indivíduos $\left.\operatorname{arm}^{-1}\right)$; riqueza (no de grupos) (Odum, 1983); índice de diversidade de Shannon, obtido pela relação: $\left(\mathrm{H}^{\prime}=-\sum\right.$ pi 1npi), em que: $\mathrm{pi}=\mathrm{ni} / \mathrm{N}$; $\mathrm{ni}$ = abundância de cada grupo e $\mathrm{N}=\mathrm{n}^{\circ}$ total de grupos (Shannon; Weaver, 1949); índice de equitabilidade de Pielou (e = H/Log $\mathrm{S}$, onde $\mathrm{H}=$ índice de Shannon e $\mathrm{S}=$ número total de grupos na comunidade) (Pielou, 1977); índice de dominância de Simpson $\left(\mathrm{S}=\sum(\mathrm{ni} / \mathrm{N}) 2\right.$, onde: $\mathrm{ni}=$ número de indivíduos do grupo i e $\mathrm{N}$ : total de indivíduos da amostra (Odum, 1983). O estimador de riqueza foi o Chao 1 (Chao $1=\mathrm{S}_{\mathrm{obs}}+\left(\mathrm{a}^{2} / 2 \mathrm{~b}\right)$, onde $\mathrm{S}_{\mathrm{obs}}$ é o número de espécies observadas nas amostras, "a" é o número de espécies representadas por apenas um espécime, e "b” é o número de espécies representado por exatamente dois espécimes.

As Classes, Ordens ou Família coletadas foram reunidas em grupos funcionais de acordo com os principais hábitos alimentares que desenvolvem no ambiente (Moço et al., 2005; Rafael et al., 2012).

\section{Análises estatísticas}

Os dados obtidos foram submetidos à análise de variância e as médias comparadas pelo teste de Scott-knott a 5\% de significância, excetuando-se a frequência e densidade relativa de organismos do solo. As análises estatísticas foram realizadas no software Sisvar (Ferreira, 2014).

A análise multivariada, com base na distância Euclidiana (Dendograma de similaridade) foi realizada utilizando o software PAST: Paleontological Statistics Software Package for Education and Data Analysis (Hammer; Harper \& Ryan, 2001).

\section{Resultados e Discussão}

\section{Umidade do solo}

Os sistemas VN e SAF apresentaram maiores teores de umidade do solo, diferindo estatisticamente $(\mathrm{p}<0,05)$ das demais áreas, que não diferiram entre si (Figura 1). Os teores de mínima e máxima da umidade do solo foi de $0,18 \mathrm{~kg} \mathrm{~kg}^{-1}$ para solo em pousio e 0,27 $\mathrm{kg} \mathrm{kg}^{-1}$ para vegetação nativa. 
Figura 1. Umidade gravimétrica do solo $\left(\mathrm{kg} \mathrm{kg}^{-1}\right)$ em sistemas de cultivo sustentáveis e convencionais. CC: cana-de-açúcar convencional; CO: cana-de-açúcar orgânica; MG: milho consorciado com guandu-anão; MM: milho orgânico em monocultivo; SAF: Sistema agroflorestal; P: solo em pousio; VN: vegetação nativa. CV\%: Coeficiente de variação.

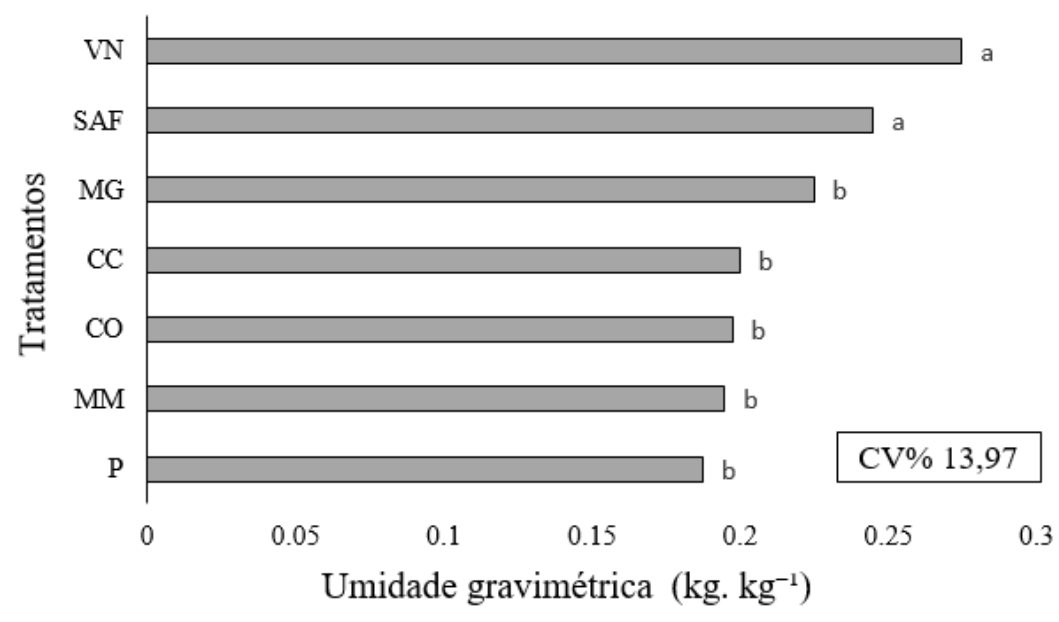

Fonte: Autores.

Os dados climáticos mostram que nas semanas que antecederam a coleta dos organismos do solo, não houve deficiência hídrica. A maior capacidade de retenção de umidade do solo no SAF e VN pode ter ocorrido em razão da maior diversidade vegetal e presença de espécies florestais nestas áreas, uma vez que áreas com maior cobertura vegetal, naturalmente apresentam maior umidade do solo (Iori et al., 2012). Isso se deve ao papel desempenhado pela serrapilheira sobre o solo em quantidades mais abundantes (G. R. Silva et al., 2020), bem como ao sombreamento causada pelas espécies florestais (Suzuki et al., 2014).

A cobertura do solo é fundamental na diminuição da evapotranspiração do horizonte superior do solo e, portanto, no aumento de retenção de umidade (May et al., 2008). Além disso, a atenuação dos raios solares que incidem sobre a copa do estrato arbóreo promove um microclima com menor evaporação de água (Tully \& Lawrence, 2012; Souza et al., 2016). Ainda, as raízes das árvores podem melhorar a infiltração de água no solo, aumentando a retenção de umidade (Martins et al., 2000), o que contribui para um ambiente mais favorável para a biota e estimula a atividade biológica (Moço et al., 2005).

O conteúdo de água é um importante regulador da vida do solo, uma vez que a maioria dos processos bioquímicos, enzimáticos, atividade e reprodução são muito dependentes da sua disponibilidade (Moreno et al., 2017). A água promove o transporte e maior disponibilidade de nutrientes no solo, favorece o crescimento das plantas e a entrada de matéria orgânica, o que beneficia a comunidade da fauna edáfica (Schwinning \& Sala, 2004).

\section{Frequência de organismos da fauna do solo}

Foram coletados um total de 1.330 indivíduos, distribuídos em 50 táxons, sendo os mais representativos Hymenoptera: Formicidae, Collembola e Diptera: Phoridae (Tabela 2). Este resultado corrobora com os estudos de outros autores (Guimarães et al., 2015; Brito et al., 2016; Guimarães et al., 2016) que, ao avaliarem diferentes sistemas de manejo e uso do solo, observaram elevada dominância dos grupos Collembola, Formicidae e Diptera nos sistemas avaliados. 
Tabela 2. Frequência relativa (\%) dos organismos da fauna do solo em diferentes sistemas de cultivo sustentáveis e convencionais. Araras, 2015.

\begin{tabular}{lccccccc}
\hline Táxons & CC & CO & MG & MM & SAF & P & VN \\
\hline $\begin{array}{l}\text { Filo Annelida } \\
\quad \text { Oligochaeta }\end{array}$ & 0,00 & 0,00 & 0,00 & 0,00 & 0,00 & 0,00 & 0,88 \\
Classe Arachnida & & & & & & & \\
$\quad$ Araneae & 1,22 & 15,0 & 4,41 & 16,0 & 9,30 & 2,86 & 0,44 \\
$\quad$ Acari & 0,00 & 0,00 & 0,00 & 0,00 & 0,00 & 0,57 & 0,00 \\
$\quad$ Acari, Ixodida & 0,00 & 0,00 & 0,00 & 0,00 & 0,39 & 0,00 & 0,00 \\
$\quad$ Opiliones & 0,00 & 0,00 & 0,00 & 0,00 & 0,00 & 0,00 & 0,44 \\
Classe Chilopoda & 0,00 & 0,00 & 0,00 & 0,00 & 0,00 & 0,00 & 0,44 \\
Classe Diplopoda & 0,00 & 0,00 & 1,47 & 3,57 & 0,39 & 0,00 & 0,00 \\
$\quad \begin{array}{l}\text { Classe Collembola } \\
\text { Classe Malacostraca }\end{array}$ & 24,9 & 0,00 & 5,88 & 0,00 & 29,0 & 62,0 & 0,00 \\
$\quad$ Ordem Isopoda & & & & & & & \\
\hline
\end{tabular}

CC: Cana-de-açúcar convencional; CO: Cana-de-açúcar orgânica; MG: Milho consorciado com guandu-anão; MM: Milho orgânico em monocultivo; SAF: Sistema agroflorestal; P: Pousio; VN: Vegetação nativa. Fonte: Autores.

No presente estudo, o grupo Hymenoptera: Formicidae se destacou, principalmente, nas áreas com CC; CO e SAF, com 64,9; 63,4 e 51,5\%, respectivamente. Os Colêmbolos foram mais predominantes nas áreas de solo em P e SAF, atingindo 62 e $29 \%$ do total da população capturada, respectivamente. Diptera: Phoridae foram encontrados exclusivamente e em quantidades significativas nos sistemas de VN e MO em MM, com 39,6 e 14,2\%, respectivamente, (Tabela 2).

O grupo Hymenoptera: Formicidae está entre os mais importantes da fauna do solo, pois é responsável por funções ecológicas, como dispersão de sementes, estruturação física e química do solo, predação, decomposição da matéria orgânica, ciclagem de nutrientes, entre outras (Bolico et al., 2012; Brito et al., 2016). Os forídeos destacam-se por sua enorme diversidade morfológica e ecológica, tanto de imaturos como de adultos (Ament, 2017). É um inseto cosmopolita, que apresenta hábito primariamente detritívoro, podendo também atuar como um predador facultativo dos imaturos de seus hospedeiros (Disney, 1994).

Por sua vez, os colêmbolos podem ser tanto saprófagos quanto predadores em termos de suas funções nos ecossistemas (Moço et al., 2005). A maioria se desenvolve no solo, alimentando-se de fungos, bactérias, algas e matéria vegetal morta (Berude et al., 2015). Por causa da abundância no solo e sensibilidade a condições ambientais, eles são considerados indicadores das condições biológicas do solo (Damé et al. 1996). Portanto, a dominância desses grupos nos sistemas estudados pode estar relacionada com o hábitat que forneça alimento, umidade, temperatura favorável e proteção às intempéries climáticas (Guimarães et al., 2015). 
Continuação. Tabela 2. Frequência relativa (\%) dos organismos da fauna do solo em diferentes sistemas de cultivo sustentáveis e convencionais. Araras, 2015.

\begin{tabular}{|c|c|c|c|c|c|c|c|}
\hline Táxons & $\mathbf{C C}$ & $\mathrm{CO}$ & MG & MM & SAF & $\mathbf{P}$ & $\mathbf{V N}$ \\
\hline \multicolumn{8}{|l|}{ Classe Insecta } \\
\hline Blattaria & 0,00 & 0,00 & 0,00 & 0,00 & 0,00 & 0,00 & 2,20 \\
\hline Blattaria, Isoptera & 0,00 & 0,00 & 0,00 & 0,00 & 0,39 & 0,00 & 0,00 \\
\hline Coleoptera, Carabidae & 0,00 & 4,76 & 7,35 & 14,29 & 0,00 & 1,43 & 0,00 \\
\hline Coleoptera, Cerambycidae & 0,00 & 0,00 & 0,00 & 1,79 & 0,00 & 0,00 & 0,00 \\
\hline Coleoptera, Chrysomelidae & 0,82 & 0,79 & 0,00 & 0,00 & 0,00 & 3,43 & 0,00 \\
\hline Coleoptera, Curculionidae & 0,00 & 0,00 & 0,00 & 0,00 & 0,39 & 0,00 & 15,8 \\
\hline Coleoptera, Elateridae & 0,00 & 0,00 & 0,00 & 5,36 & 0,00 & 0,00 & 0,00 \\
\hline Coleoptera, Meloidae & 0,00 & 0,00 & 0,00 & 1,79 & 0,00 & 0,00 & 0,00 \\
\hline Coleoptera, Scarabaeidae & 0,41 & 0,79 & 0,00 & 1,79 & 2,71 & 0,00 & 0,00 \\
\hline Coleoptera, Staphylinidae & 0,00 & 0,00 & 0,00 & 0,00 & 0,00 & 0,29 & 1,32 \\
\hline Coleoptera, Tenebrionidae & 0,00 & 0,79 & 0,00 & 0,00 & 0,00 & 0,00 & 0,00 \\
\hline Larva de Coleoptera & 0,00 & 0,00 & 7,35 & 3,57 & 0,00 & 0,29 & 0,00 \\
\hline Dermaptera, Forficulidae & 0,00 & 0,00 & 0,00 & 1,79 & 0,00 & 0,00 & 0,00 \\
\hline Dermaptera, Spongiphoridae & 0,00 & 1,59 & 0,00 & 0,00 & 0,78 & 0,00 & 1,76 \\
\hline Diptera, Agromyzidae & 0,00 & 0,00 & 0,00 & 0,00 & 0,00 & 1,14 & 0,88 \\
\hline Diptera, Calliphoridae & 0,00 & 0,00 & 1,47 & 0,00 & 0,39 & 0,29 & 0,00 \\
\hline Diptera, Cecidomyiidae & 0,00 & 0,00 & 0,00 & 0,00 & 0,00 & 2,57 & 0,00 \\
\hline Diptera, Phoridae & 0,00 & 0,00 & 0,00 & 14,2 & 0,00 & 0,00 & 39,6 \\
\hline Diptera, Scatopsidae & 0,82 & 0,00 & 0,00 & 0,00 & 0,00 & 0,00 & 0,00 \\
\hline Diptera, Sciaridae & 0,00 & 0,00 & 1,47 & 0,00 & 0,39 & 0,57 & 0,00 \\
\hline Diptera, Stratiomyidae & 0,00 & 0,00 & 0,00 & 0,00 & 0,00 & 0,00 & 0,44 \\
\hline Diptera, Tachinidae & 0,00 & 0,00 & 0,00 & 0,00 & 0,00 & 0,00 & 0,44 \\
\hline Diptera, Tipulidae & 0,00 & 0,00 & 0,00 & 5,36 & 0,00 & 0,00 & 0,00 \\
\hline Diptera, Ulidiidae & 0,00 & 0,00 & 0,00 & 1,79 & 0,00 & 0,00 & 0,00 \\
\hline Larva de Diptera & 0,00 & 0,00 & 39,7 & 12,5 & 0,00 & 0,00 & 0,00 \\
\hline Hemiptera, Cicadellidae & 0,00 & 5,56 & 4,41 & 1,79 & 0,00 & 3,43 & 0,00 \\
\hline Hemiptera, Cydnidae & 0,00 & 0,00 & 0,00 & 0,00 & 1,94 & 0,00 & 0,00 \\
\hline Hemiptera, Pentatomidae & 0,00 & 0,00 & 0,00 & 1,79 & 0,00 & 0,00 & 0,00 \\
\hline Hemiptera, Rhopalidae & 0,00 & 0,00 & 0,00 & 3,57 & 1,16 & 0,86 & 0,00 \\
\hline Ninfa de Hemiptera & 0,00 & 0,00 & 0,00 & 1,79 & 0,00 & 4,57 & 0,00 \\
\hline Hymenoptera, Apidae & 0,00 & 0,00 & 0,00 & 0,00 & 0,00 & 0,29 & 0,00 \\
\hline Hymenoptera, Formicidae & 64,9 & 63,4 & 1,47 & 0,00 & 51,5 & 12,8 & 11,0 \\
\hline Hymenoptera, Ichneumonidae & 0,00 & 0,00 & 0,00 & 1,79 & 0,00 & 0,00 & 0,00 \\
\hline Hymenoptera, Pompilidae & 0,00 & 0,00 & 0,00 & 1,79 & 0,00 & 0,00 & 0,00 \\
\hline Hymenoptera, Scollidae & 0,00 & 0,79 & 0,00 & 0,00 & 0,00 & 0,00 & 0,00 \\
\hline Lepidoptera, Hesperiidae & 0,00 & 0,00 & 0,00 & 0,00 & 0,00 & 0,57 & 0,00 \\
\hline Larva de Lepidoptera & 0,00 & 5,56 & 7,35 & 0,00 & 0,00 & 0,00 & 0,00 \\
\hline Orthoptera, Acrididae & 0,00 & 0,00 & 0,00 & 0,00 & 0,00 & 0,29 & 0,00 \\
\hline Orthoptera, Anostostomatidae & 0,41 & 0,00 & 0,00 & 0,00 & 0,00 & 1,14 & 0,00 \\
\hline Orthoptera, Gryllidae & 6,12 & 0,79 & 17,6 & 3,57 & 1,16 & 0,00 & 0,44 \\
\hline Ninfa de Orthoptera & 0,00 & 0,00 & 0,00 & 0,00 & 0,00 & 0,57 & 0,00 \\
\hline
\end{tabular}

CC: Cana-de-açúcar convencional; CO: Cana-de-açúcar orgânica; MG: Milho consorciado com guandu-anão; MM: Milho orgânico em monocultivo; SAF: Sistema agroflorestal; P: Pousio; VN: Vegetação nativa. Fonte: Autores.

\section{Grupos funcionais}

Os grupos da fauna do solo capturados se enquadram em seis grupos funcionais, sendo: saprófago, predador, saprófagopredador, fitófagos, micrófagos e outros. Os predadores foram mais expressivos na maioria dos sistemas, representando 66,12; 83,33; 
39,23 e 61,24\% no solo com CC, MO em MM e SAF, respectivamente (Figura 2). Este resultado está associado a dominância elevada de Hymenoptera: Formicidae nessas áreas, principalmente nos sistemas com CC, CO e SAF (Tabela 2).

Figura 2. Densidade relativa (\%) dos grupos funcionais dos organismos da fauna do solo em diferentes sistemas de cultivo sustentáveis e convencionais. Araras, SP, 2015. CC: Cana-de-açúcar convencional; CO: Cana-de-açúcar orgânica; MG: Milho consorciado com guandu-anão; MM: Milho orgânico em monocultivo; SAF: Sistema agroflorestal; P: Pousio; VN: Vegetação nativa.

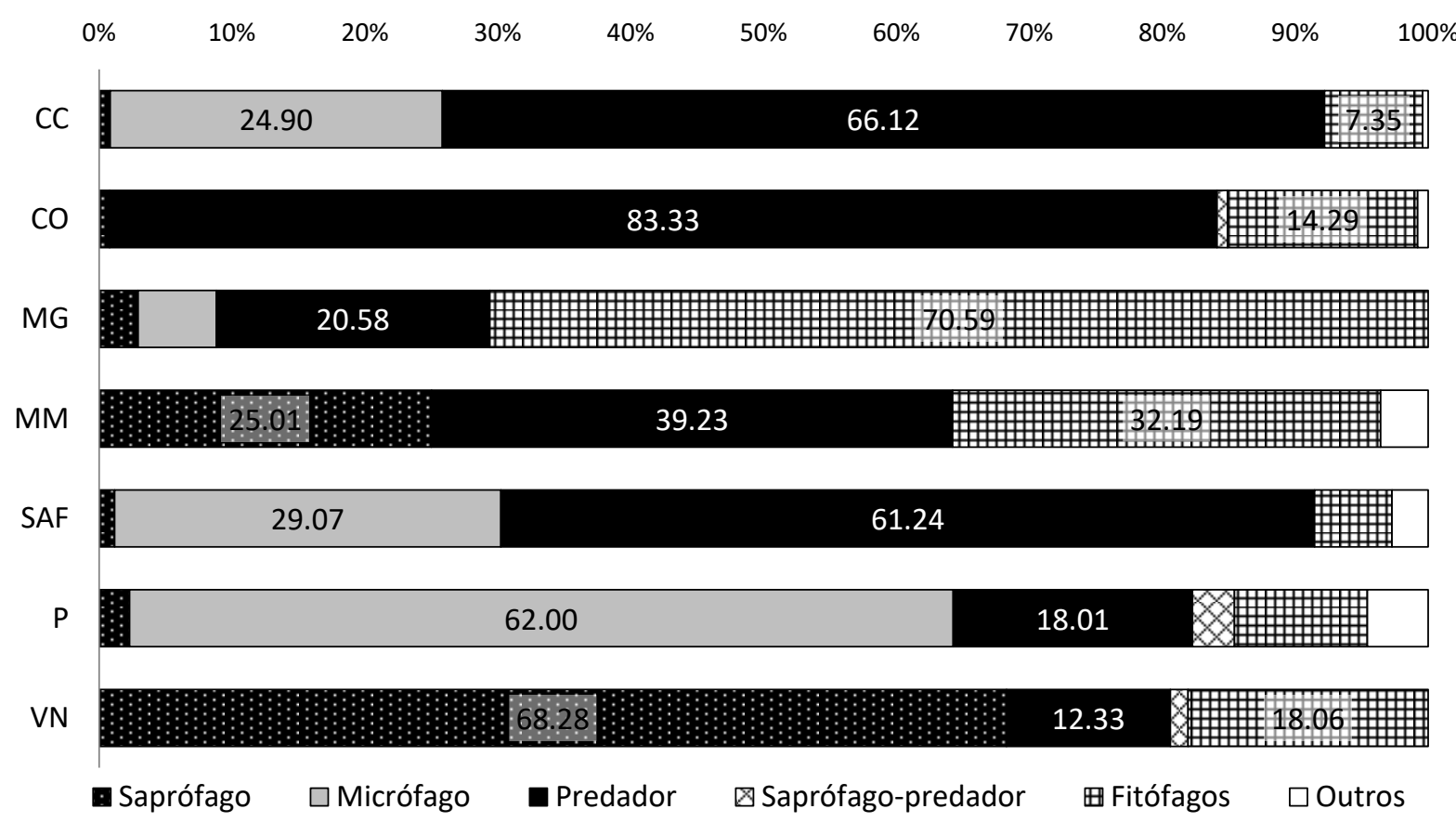

Fonte: Autores.

As formigas desempenham um papel significativo nos ecossistemas tropicais como resultado de sua alta diversidade, abundância e comportamento como predadoras (Carroll \& Janzen, 1973). Segundo Moço et al. (2005), o grupo Formicidae regula as populações de outros grupos de invertebrados do solo, portanto, esses organismos possuem papel importante no controle de pragas (Ropero \& Armbrecht, 2005).

Os fitófagos foram mais representativos no solo com MG, com 79,59\% (Figura 2). Vale ressaltar que nesse sistema houve baixa densidade de predadores, resultados que divergem dos observados por outros autores (Bastos et al., 2003; Fernandes et al., 2010), onde a ocorrência elevada de fitófagos explicou a presença de predadores em altas populações. Portanto, no presente estudo, a baixa população de predadores não contribuiu para o controle das populações de fitófagos (Marasas et al., 2010).

No sistema solo em $\mathrm{P}$, os micrófagos foram dominantes, atingindo $63 \%$ do total de indivíduos em função dos grupos funcionais (Figura 2). Este resultado está associado a alta representatividade do grupo Collembola (Tabela 2), que desenvolvem a atividade predatória de microrganismos (Tordoff et al., 2008). A presença de micrófagos é de grande importância para a decomposição do material orgânico presente no solo (Almeida et al., 2017). Influenciam a fertilidade do solo, estimulando a atividade microbiana, dispersando esporos de fungos e controlando o crescimento de fungos e bactérias causadores de doenças em plantas (Berude et al., 2015). Além disso, são indicadores da qualidade do solo, pois são abundantes, sensíveis a alterações ambientais e apresentam diversidade elevada (Maunsell et al., 2012). No sistema de VN (Figura 2), o grupo funcional mais representativo foi de saprófagos, que tem relação com a elevada densidade de Diptera: Phoridae e Isopoda; juntos somaram 63,3\% do total de organismos capturados na mata (Tabela 2). Os saprófagos caracterizam-se por se alimentarem diretamente dos resíduos de plantas, fragmentando-os (Moço et al., 2005), contribuindo para a decomposição da serapilheira, redistribuição de matéria orgânica e ciclagem de nutrientes no ambiente 
(Correia \& Andrade, 1999). Florestas com vegetação diversa tendem a ter uma fauna de solo mais rica e a ser mais abundantes em espécies saprófagas (Menezes et al., 2009), em função do rápido crescimento das plantas com aumento da produção de serapilheira, fornecimento de condições de temperatura e umidade e melhoria na qualidade de recursos alimentares (Barros et al., 2003; Salamon et al., 2008). Os saprófagos são extremamente sensíveis às mudanças ambientais, o que reforça a sua importância como indicador em estudos sobre a fauna do solo e a decomposição da serapilheira (Resende et al., 2013).

\section{Abundância, riqueza e índices ecológicos}

Para abundância de organismos da fauna do solo, verificou-se diferença significativa $(p<0,05)$ entre os sistemas avaliados (Figura 3A). As áreas P, SAF, CC e VN foram estatisticamente semelhantes entre si e superiores em relação aos demais sistemas (CO, MG e MM). Estes resultados corroboram, em partes, com os obtidos por outros autores (Lima et al., 2010; Guimarães et al., 2015; Pereira et al., 2017; D. C. Silva et al., 2020) que, ao avaliarem a fauna edáfica em diferentes sistemas de uso do solo, observaram maiores abundâncias de organismos em áreas com maior diversidade vegetal (mata nativa e SAF). Áreas com maior complexidade estrutural da vegetação proporcionam um ambiente favorável para o estabelecimento e desenvolvimento da fauna do solo (Machado et al., 2015), em virtude da maior disponibilidade de nichos ecológicos, abrigo e recursos alimentares, associado ao menor risco de predação (Silva et al., 2012).

Guimarães et al. (2016), avaliando a estrutura da comunidade da fauna do solo em sistemas de cultivo do cafeeiro, verificaram maior abundância de organismos no solo em pousio em comparação com áreas de cafeeiro exclusivo, ou consórcio com espécies arbóreas e $B$. decumbens e vegetação nativa. Para os autores, isto ocorreu pelo fato do pousio ser uma técnica para recuperação do solo após cultivo, em que o solo não é manejado. O não revolvimento do solo, aplicação de agroquímicos e trânsito de maquinário agrícola favorece os organismos do solo sensíveis às variações nas práticas de manejo, como sistema de cultivo, adubação, calagem e aplicação de defensivos agrícolas (Drescher et al., 2011). Além disso, áreas com vegetação espontânea podem ser fontes de abrigo e alimentação para os organismos do solo (Marasas et al., 2010).

Estes fatores podem explicar o fato de o $\mathrm{P}$ ter sido semelhante às áreas VN e SAF em função da abundância de indivíduos da fauna do solo no presente estudo (Figura 3A). O CC foi semelhante ao P, SAF e VN, provavelmente pela elevada presença de indivíduos dos grupos Hymenoptera: Formicidae e Collembola (Tabela 2). Outros autores já observaram presença elevada de Collembola em áreas com manejo convencional em comparação a sistemas mais complexos, como plantio direto, consórcio de culturas, SAF e mata nativa (Alves et al., 2006; Balin et al., 2017; Sales et al., 2018). Segundo Gatiboni et al. (2011), a redução da cobertura do solo provoca a diminuição da diversidade de organismos da fauna edáfica, com aumento relativo de organismos da ordem Collembola.

As formigas possuem alguns gêneros que apresentam preferência por ambientes simplificados, perturbados e mais abertos (Lutinski \& Garcia, 2005; Almeida et al., 2007), com predomínio de gramíneas e elevada incidência de luz diretamente no solo (Veiga et al., 2015). Além disso, a frequência de formigas é maior quando há redução da umidade do solo e aumento da temperatura do ar (Santos et al., 2012). Portanto, no presente estudo, o ambiente simplificado, mais aberto e com menor retenção de umidade do solo (Figura 1) do monocultivo de cana pode explicar a dominância de Formicidae no CC, influenciando na abundância de organismos neste sistema. 
Figura 3. Abundância de organismos (A), riqueza de grupos (B) e índice de equitabilidade (C) da fauna em diferentes sistemas de cultivo sustentáveis e convencionais, Araras, SP, 2015. CC: Cana-de-açúcar convencional; CO: Cana-de-açúcar orgânica; MG: Milho consorciado com guandu-anão; MM: Milho orgânico em monocultivo; SAF: Sistema agroflorestal; P: Pousio; VN: Vegetação nativa. CV\%: Coeficiente de variação.
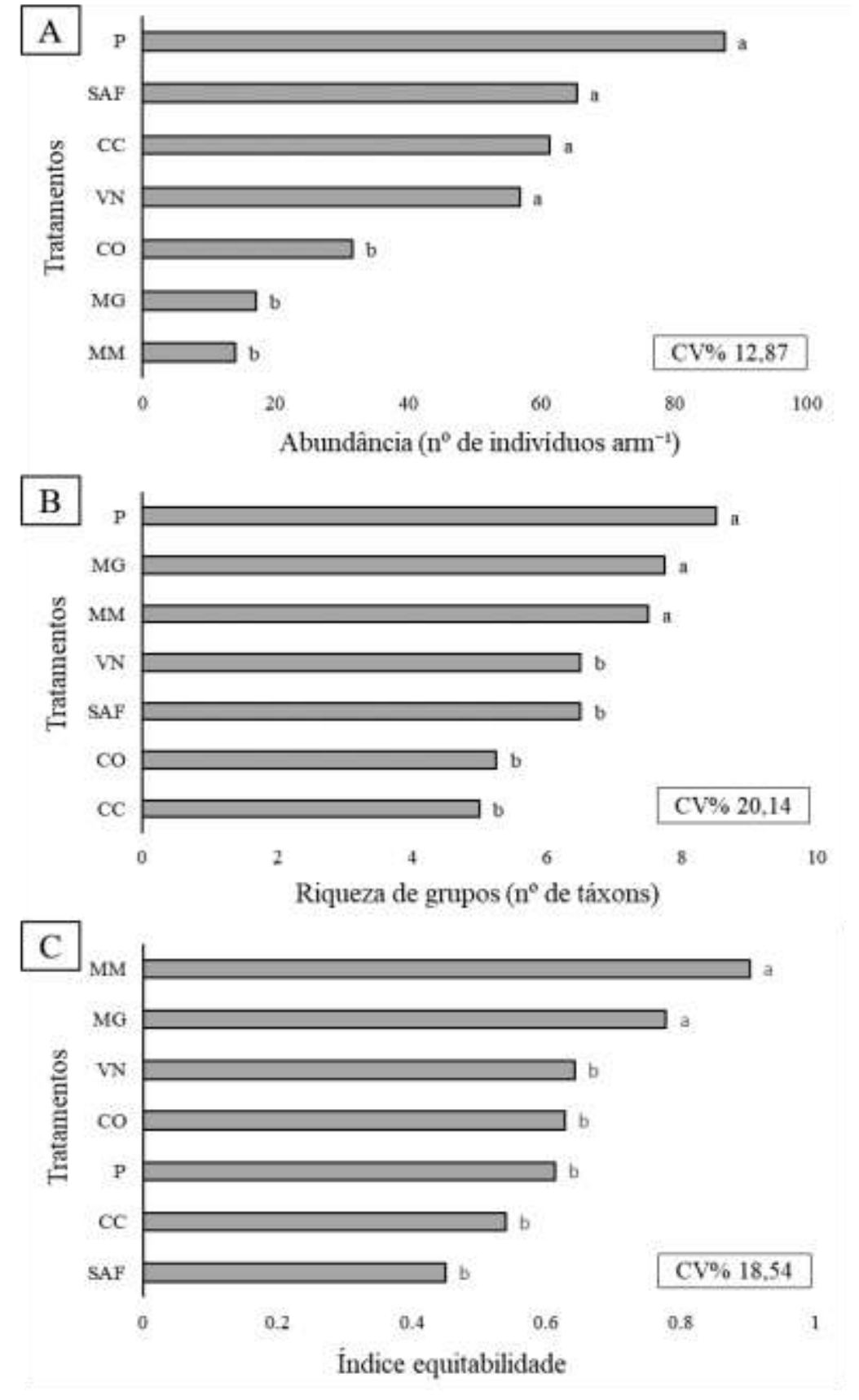

Fonte: Autores

Houve diferença significativa ( $\mathrm{p}<0,05$ ) entre as áreas estudadas para variável riqueza de grupos (Figura 3B), em que P, MG e MM foram superiores a VN, SAF, CO e CC, sem, no entanto, diferirem estatisticamente entre si. Estes resultados corroboram, em parte, com os achados de Brito et al. (2016) que, ao avaliarem a fauna epigéica e edáfica em cultivos de mandioca consorciada com adubos verdes, concluíram que o consórcio com guandu-anão proporcionou maior riqueza à comunidade da fauna edáfica.

No que diz respeito aos sistemas P e MM, outros autores observaram valores de riqueza de grupos maiores ou semelhantes em sistemas de monocultivo e pousio (Silva et al., 2013; Fernandes et al., 2015; Guimarães et al., 2016; Sales et al., 2018) em relação a sistemas mais complexos. Cabe ressaltar que P, MM e MG apresentaram, de maneira geral, menores representatividades de 
predadores (Figura 2), o que pode explicar os maiores valores de riqueza de grupos nestes sistemas; uma vez que a presença de predadores contribui no controle das populações de outros grupos funcionais da fauna edáfica (Marasas et al., 2010).

Em relação aos índices ecológicos de diversidade (Shannon), dominância (Simpson) e riqueza (Chao-1), não foram observadas diferença significativas ( $\mathrm{p}>0,05$ ) entre as áreas estudadas (Tabela 3 ).

Tabela 3. Índice de diversidade " $\alpha$-alfa" (Shannon), índice de dominância (Simpson) e índice de riqueza (Chao-1) da fauna do em diferentes sistemas de cultivo sustentáveis e convencionais. Araras, SP, 2015.

\begin{tabular}{lccc}
\hline \multirow{2}{*}{ Tratamentos } & Diversidade $\alpha$ & Dominância & Riqueza \\
\cline { 2 - 4 } & Shannon & Simpson & Chao-1* \\
\hline VN & $1,16^{\text {NS** }}$ & $0,41^{\text {NS }}$ & $7,43^{\text {NS }}$ \\
P & 1,29 & 0,41 & 9,87 \\
MM & 1,71 & 0,22 & 10,12 \\
MG & 1,25 & 0,39 & 11,25 \\
CC & 0,83 & 0,55 & 6,75 \\
CO & 1,04 & 0,49 & 6,50 \\
SAF & 0,83 & 0,62 & 8,33 \\
\hline CV\% & 26,79 & 33,59 & 27,32 \\
\hline
\end{tabular}

*Dados transformados com base na expressão Log(x). **NS: Não significativo pelo teste F. CC: Cana-de-açúcar convencional; CO: Cana-de-açúcar orgânica; MG: Milho consorciado com guandu-anão; MM: Milho orgânico em monocultivo; SAF: Sistema agroflorestal; P: Pousio; VN: Vegetação nativa. CV\%: Coeficiente de variação. Fonte: Autores.

Contudo, houve diferença estatística significativa $(\mathrm{p}<0,05)$ para índice de equitabilidade (Figura 3C). Os sistemas com milho orgânico em monocultivo e em consórcio com guandu-anão (MM e MG) foram estatisticamente semelhantes e superiores a VN, CO, P, CC e SAF.

O índice de equitabilidade de Pielou varia de 0 a 1, sendo que quanto menor o índice maior será a dominância por poucos grupos (Pasqualin et al., 2012). Vale ressaltar que, no presente estudo, os sistemas MM e MG apresentaram baixa dominância de um único grupo sobre os demais (Tabela 2). De maneira geral onde há maior equitabilidade e os grupos se distribuem melhor pelo sistema, há menor dominância de grupos, e o contrário também pode ser observado (Santos et al., 2015).

Além disso, os sistemas MM e MG apresentaram os menores valores de abundância de indivíduos da fauna do solo (Figura 3A) e os maiores valores de riqueza de grupos (semelhante ao sistema P) (Figura 3B). Consequentemente, eles mostraram maior uniformidade na distribuição dos organismos da fauna do solo entre os grupos, com índices de equitabilidade de Pielou mais próximos de 1 (Figura 3C). Quanto maior a abundância da fauna do solo em determinado componente, maior a chance da predominância de um grupo, reduzindo a equitabilidade (Nunes et al., 2008), pois a diversidade de grupos está associada a uma relação entre número de grupos (riqueza de grupos) e a distribuição do número de indivíduos entre os grupos (Walker, 1989).

\section{Análise de agrupamento}

Com base na análise de agrupamento, observou-se a formação de dois grandes grupos distintos, com relação à fauna do solo (Figura 4). Esses dois grupos não apresentaram nenhuma similaridade entre si, uma vez que a sua distância de ligação foi de $100 \%$. 
Figura 4. Dendograma de dissimilaridade da fauna em diferentes sistemas de cultivo do solo. Araras, SP, 2015. CC: cana-de-açúcar convencional; CO: cana-de-açúcar orgânica; MG: milho consorciado com guandu-anão; MM: milho orgânico em monocultivo; SAF: sistema agroflorestal; P: Pousio; VN: vegetação nativa.

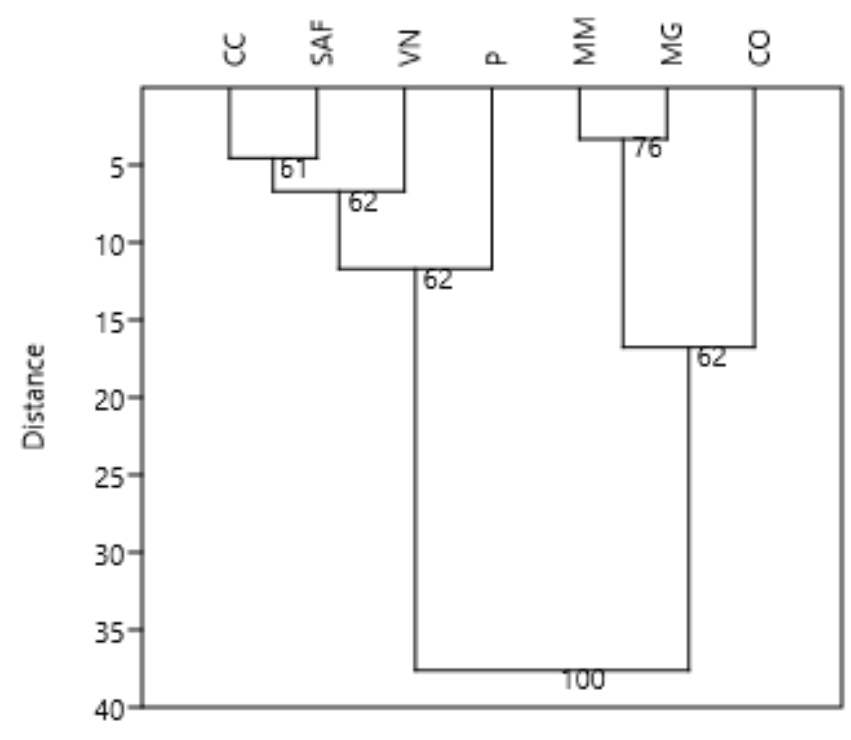

Fonte: Autores

O primeiro grupo engloba os sistemas CC, SAF, VN e P, que apresentaram alta similaridade entre si, provavelmente relacionada com a semelhança entre estes sistemas no que diz respeito a densidade de organismos da fauna do solo (Figura 3A). Dentro desse grande grupo houve a separação em dois subgrupos, sendo um formado pelos sistemas de cultivo (CC e SAF) e outro pelos sistemas de referência da qualidade do solo ( $\mathrm{P} \mathrm{e} \mathrm{VN}$ ). A formação do subgrupo com $\mathrm{P} \mathrm{e} \mathrm{VN} \mathrm{permite} \mathrm{inferir} \mathrm{que} \mathrm{os} \mathrm{sistemas} \mathrm{com} \mathrm{menor}$ interferência antrópica atuam de forma semelhantes sobre a comunidade da fauna do solo, uma vez que atingiram valores muito próximos entre si no que se refere aos índices ecológicos da comunidade da fauna do solo (Figura 3C e Tabela 3).

O segundo grupo compreendeu os sistemas sob manejo orgânico (MM, MG e CO) (Figura 4). Dentro deste mesmo grupo, observou-se a formação de dois subgrupos independentes e distantes. Em um dos subgrupos, os sistemas de milho (MM e MG) se mostraram muito similares entre si. Este agrupamento ocorreu em função dos valores próximos entre si para as variáveis abundância de indivíduos (Figura 3A), riqueza de grupos (Figura 3B) e índice de equitabilidade (Figura 3C). Esse resultado permite afirmar que esta gramínea, quando cultivada organicamente, teve efeito semelhante sobre os invertebrados do solo, independente do cultivo solteiro ou em consórcio. O sistema $\mathrm{CO}$ se isolou, o que permite inferir uma dissimilaridade significativa entre o sistema de cana orgânica e as áreas de milho orgânico solteiro e consorciado (Figura 4).

\section{Conclusões}

O grupo Hymenoptera: Formicidae foi o mais representativo nos sistemas estudados, seguidos por Collembola e Diptera: Phoridae.

As áreas CC e SAF influenciam a abundância de organismos de maneira semelhante às áreas referenciais de qualidade do solo $(\mathrm{P} \mathrm{e} \mathrm{VN)}$

Os sistemas MM, MG e P favorecem a riqueza de grupos da fauna edáfica, com as duas áreas de milho mostrando maior uniformidade na distribuição dos grupos de invertebrados do solo.

Áreas sob manejo orgânico influenciam de maneira semelhante a fauna invertebrada.

Os resultados obtidos podem auxiliar na classificação de alguns grupos de invertebrados como bioindicadores de qualidade do solo em agroecossistemas. 


\section{Agradecimentos}

Ao Programa de Melhoramento Genético de Cana-de-Açúcar da UFSCar e ao professor Dr. Luiz Antônio Correia Margarido, por disponibilizar as áreas estudadas e as informações necessárias para descrever os sistemas.

\section{Conflito de interesses}

Os autores declaram não haver conflito de interesses.

\section{Referências}

Ament, D. C. (2017). Lista das espécies de Phoridae (Insecta, Diptera) do estado do Mato Grosso do Sul. Iheringia: Série Zoologia, 107, e2017136.

Almeida, F. S., Queiroz, J. M., \& Mayhé-Nunes, A. J. (2007). Distribuição e abundância de ninhos de Solenopsis invicta Buren (Hymenoptera: Formicidae) em um agroecossistema diversificado sob manejo orgânico. Floresta e Ambiente, 14(1), 33-43.

Almeida, H. S., Silva, R. F., Grolli, A. L., \& Scheid, D. L. (2017). Ocorrência e diversidade da fauna edáfica sob diferentes sistemas de uso do solo. Revista Brasileira de Tecnologia Agropecuária, 1(1), 15-23.

Alves, M.V., Baretta, D., \& Cardoso, E. B. J. (2006). Fauna edáfica em diferentes sistemas de cultivo no estado de São Paulo. Revista de Ciências Agroveterinárias, 5(1), 31-41.

Amazonas, N. T., Viani, R. A. G., Rego, M. G. A., Camargo, F. F., Fujihara, R. T., \& Valsechi, O. A. (2018). Soil macrofauna density and diversity across a chronosequence of tropical forest restoration in Southeastern Brazil. Brazilian journal of biology, 78(3), 449-456.

Assad, M. L. L. (1997). Fauna do solo. In: Vargas, M. A. T., Hungria, M. (Ed.). Biologia dos solos dos cerrados. Planaltina: EMBRAPA.

Assad, M. L. L., Brossarde, M., \& Dias, V. D. S. (1997, julho). Atividade biológica em solos da região dos Cerrados. Anais do Congresso Brasileiro de Ciência do Solo. Seropédica, RJ, Brasil, 26.

Balin, N. M., Bianchini, C., Ziech, A. R. D., Luchese, A. V., Alves, M. V., \& Conceição, P. C. (2017). Fauna edáfica sob diferentes sistemas de manejo do solo para produção de cucurbitáceas. Scientia Agraria, 18(3), 74-84.

Bastos, C. S., Picanço, M. C., Galvão, J. C. C., Cecon, P. R., \& Pereira, P. R. G. (2003). Incidência de insetos fitófagos e de predadores no milho e no feijão cultivados em sistema exclusivo e consorciado. Ciência Rural, 33(3), 391-397.

Barros, E., Neves, A., Blanchart, E., Fernandes, E.C., Wandelli, E., \& Lavelle, P (2003). Development of the soil macrofauna community under silvopastoral and agrosilvicultural systems in Amazonia. Pedobiologia, 47(3), 273-280.

Bender, S. F., Wagg, C., \& Van Der Heijden, M. G. A. (2016). An underground revolution: biodiversity and soil ecological engineering for agricultural sustainability. Trends in Ecology \& Evolution, 31(6), 440-452.

Berude, M., Galote, J. K. B., Pinto, P. H., \& Amaral, A. A. A. (2015). A mesofauna do solo e sua importância como bioindicadora. Enciclopédia Biosfera: Centro Científico Conhecer, 11(22), 14-28.

Bolico, C.F., Oliveira, E.A., Gantes, M.L., Dumont, L.F.C., Carrasco, D.S., D’Incao, F. \& (2012). Mirmecofauna (Hymenoptera, Formicidae) de duas marismas do Estuário da Lagoa dos Patos, RS: diversidade, flutuação de abundância e similaridade como indicadores de conservação. EntomoBrasilis, 5(1), 11-20.

Bommarco, R., Kleijn, D., \& Potts, S. G. (2013). Ecological intensification: harnessing ecosystem services for food security. Trends in Ecology \& Evolution, 28(4), 230238.

Brito, M. F., Tsujigushi, B. P., Otsubo, A. A., Silva, R. F., \& Mercante, F. M. (2016). Diversidade da fauna edáfica e epigeica de invertebrados em consórcio de mandioca com adubos verdes. Pesquisa Agropecuária Brasileira, 51(3), 253-260.

Brussaard, L., De Ruiter, P. C., \& Brown, G. G. (2007). Soil biodiversity for agricultural sustainability. Agriculture, Ecosystems \& Environment, $121(3)$, $233-244$.

Carroll, C. R., \& Janzen, D. H. (1973). Ecology of foraging by ants. Annual Review of Ecology and Systematics, 4, $231-257$.

Chabert, A. \& Sarthou, J. P. (2020). Conservation agriculture as a promising trade-off between conventional and organic agriculture in bundling ecosystem services. Agriculture, Ecosystems \& Environment, 292, e106815.

Claessen, M. E. C. (1997). Manual de métodos de análise de solo. EMBRAPA-CNPS.

Correia, M. E. F. \& Andrade, A. G. (1999). Formação da serapilheira e ciclagem de nutrientes. In: Santos, G.A., Camargo, F. A. O. (Ed.). Fundamentos da matéria orgânica do solo ecossistemas tropicais e subtropicais. Porto Alegre: Genesis.

Damé, P. R. V., Quadros, F. L. F., Kersting, C. E. B., Trindade, J. P. P., \& Antoniolli, Z. I. (1996). Efeitos da queimada seguida de pastoreio ou diferimento sobre o resíduo, temperatura do solo e mesofauna de uma pastagem natural. Ciência Rural, 26(3), 391-396.

Disney, R. H. L. (1994). Scuttle flies: The Phoridae. Chapman \& Hall. 
Drescher, M. S., Rovedder, A. P. M., Antoniolli, Z. I., Eltz, F. L. F., \& Drescher, G. L. (2011). Fauna epigeica em sistemas de produção de Nicotiana tabacum L. Revista Brasileira de Ciência do Solo, 35(5), 1499-1508.

Duru, M., Therond, O., Martin, G., Martin-Clouaire, R., Magne, M. A., Justes, E., Journet, E. P., Aubertot, J. N., Savary, S., Bergez, J. E., Sarthou, J. P (2015). How to implement biodiversity based agriculture to enhance ecosystem services: a review. Agronomy for Sustainable Development, 35: 1259-1281.

Ecovia Intelligence (2020). The Global Market for Organic Food \& Drink: Statistics \& Emerging Trends 2020. Germany: Medienhaus Plump.

Empresa Brasileira de Pesquisa Agropecuária (2006). Sistema brasileiro de classificação de solos. EMBRAPA-Solos.

Emmerson, M., Morales, M. B., Oñate, J. J., Batáry, P., Berendse, F., Liira, J., \& Bengtsson, J. (2016). How agricultural intensification affects biodiversity and ecosystem services. In: Dumbrell, A. J., Kordas, R. L., \& Woodward, G. (ed.) (2016). Advances in ecological research. Oxford: Academic Press.

Feigl, B. J., Oliveira, B. G., Franco, A. L. C., \& Frazão, L. A. (2019). Inter-relação entre manejo e atributos biológicos do solo. In: Bertol, I., De Maria, I. C., Souza, I. S. (Ed.). Manejo e conservação do solo e da água. Viçosa: Sociedade Brasileira de Ciência do Solo.

Fernandes, F. L., Picanço, M. C., Fernandes, M. E. S., Xavier, V. M., Martins, J. C., \& Silva, V. F. (2010). Controle biológico natural de pragas e interações ecológicas com predadores e parasitoides em feijoeiro. Bioscience Journal, 26(1), 6-14.

Fernandes, M. M., Veloso, M. E. C., Silva, M. D., Fernandes, M. R. M., \& Lima, N. N. C. (2015). Fauna edáfica de área degradada revegetada com pinhão manso em monocultivo e consórcio com Andropogon gayanos L. Revista Energia na Agricultura, 30(1), 47-52.

Ferreira, D. F. (2014). Sisvar: a Guide for its Bootstrap procedures in multiple comparisons. Ciência e Agrotecnologia, 38(2), 109-112.

Gatiboni, L. C., Coimbra, J. L. M., Denardin, R. B. N., \& Wildner, L. P. (2011). Microbial biomass and soil fauna during the decomposition of cover crops in notillage system. Revista Brasileira de Ciência do Solo, 35(4), 1151-1157.

Green, R. E., Cornell, S. J., Scharlemann, J. P. W., \& Balmford, A. (2005). Farming and the fate of wild nature. Science, 307(5709), 550-555.

Guimarães, N. F., Fontanetti, A., Fujihara, R.T., Gallo, A. S., Souza, M. D. B., \& Morinigo, K. P. G. (2016). Fauna invertebrada epigéica associada a diferentes sistemas de cultivo do cafeeiro. Coffee Science, 11(4), 484-494.

Guimarães, N. F., Gallo, A. S., Souza, M. D. B., Agostinho, P. R., Gomes, M. S., \& Silva R. F. (2015). Influência de sistemas de produção de café orgânico arborizado sobre a diversidade da fauna invertebrada epigéica. Coffee Science, 10(3), 280-288.

Hammer, Ø., Harper, D. A., \& Ryan, P. D. (2001). PAST: Paleontological statistics software package for education and data analysis. Palaeontologia electronica, 4(1), 19.

Hopkin, S. P., \& Read, H. J. (1992). The biology of millipedes. Oxford University Press.

Iori, P., Dias Júnior, M. S., \& Silva, R. B. (2012). Resistência do solo à penetração e ao cisalhamento em diversos usos do solo em áreas de preservação permanente. Bioscience Journal, 28(1), 185-95.

Köppen, W., Geiger, R. (1928). Klimate der Erde. Verlag Justus Perthes.

Kremen, C. \& Miles, A, (2012). Ecosystem services in biologically diversified versus conventional farming systems: benefits, externalities, and trade-offs. Ecology and Society, 17(4), 1-25.

Lima, S. S., Aquino, A. M., Leite, L. F. C., Velásquez, E., \& Lavelle, P. (2010). Relação entre macrofauna edáfica e atributos químicos do solo em diferentes agroecossistemas. Pesquisa Agropecuária Brasileira, 45(3), 322-331.

Lutinski, J. A., \& Garcia, F. R. M. (2005). Análise faunística de Formicidae (Hymenoptera: Apocrita) em ecossistema degradado no município de Chapecó, Santa Catarina. Biotemas, 18(2), 73-86.

Machado, D. L., Pereira, M. G., Correia, M. E. F., Diniz, A. R., \& Menezes, C. E. G. (2015). Fauna edáfica na dinâmica sucessional da Mata Atlântica em floresta estacional semidecidual na bacia do Rio Paraíba do Sul-RJ. Ciência Florestal, 25(1), 91-106.

Marasas, M., Sarandón, S., \& Cicchino, A. (2010). Semi-natural habitats and field margins in a typical agroecosystem of the Argentinean pampas as a reservoir of carabid beetles. Journal of Sustainable Agriculture, 34(2), 153-168.

Martins, E., Neves, E., Ferreira, C., \& Shimizu, J. (2000). Deposição de serrapilheira e nutrientes em povoamentos de grevílea de diferentes origens no sudoeste do Paraná. Anais Congresso Brasileiro de Sistemas Agroflorestais, Manaus, AM, Brasil, 3.

Maunsell, S. C., Kitching, R. L., Greenslade, P., Nakamura, A., \& Burwell, C. J. (2012). Springtail (Collembola) assemblages along an elevational gradiente in Australian subtropical rainforest. Australian Journal of Entomology, 52(2), 114-124.

May, P. H., \& Trovatto, C. M. M. (2008). Manual agroflorestal para a Mata Atlântica. Brasília: Ministério do Desenvolvimento Agrário, Secretaria de Agricultura Familiar.

Melo, F. V., Brown, G. G., Constantino, R., Louzada, J. N., Luizão, F. J., de Morais, J. W., \& Zanetti, R. (2009). A importância da meso e macrofauna do solo na fertilidade e como bioindicadores. Boletim Informativo da Sociedade Brasileira de Ciência do Solo, 34(1), 38-43.

Menezes, C. E. G., Correia, M. E. F., Pereira, M. G., Batista, I., Rodrigues, K. M., Couto, W., Anjos, L. H. C., \& Oliveira, I. P. (2009). Macrofauna edáfica em estádios sucessionais de floresta estacional e pastagem mista em Pinheiral (RJ). Revista Brasileira de Ciência do Solo, 33(6), 1647-1656.

Moço, M. K. S., Gama-Rodrigues, E. F., Gama-Rodrigues, A. C., \& Correia, M. E. F. (2005). Caracterização da fauna edáfica em diferentes coberturas vegetais na região Norte Fluminense. Revista Brasileira de Ciência do Solo, 29(4), 555-564 
Moreno, J. L., Bastida, F., Ondoño, S., García, C., Andrés-Abellán, M., \& López-Serrano, F. R. (2017). Agro-forestry management of Paulownia plantations and their impact on soil biological quality: the effects of fertilization and irrigation treatments. Applied Soil Ecology, 117: 46-56.

Nunes, L. A. P. L., Araújo Filho, J. A., \& Menezes, R. I. Q. (2008). Recolonização da fauna edáfica em áreas de caatinga submetidas a queimadas. Caatinga, 21(3), 214-220.

Odum, E. P (1983). Ecologia. Rio de Janeiro: Guanabara.

Pasqualin, L. A., Dionísio, J. A., Zawadneak, M. A. C., \& Marçal, C. T. (2012). Macrofauna edáfica em lavouras de cana-de-açúcar e mata no noroeste do Paraná - Brasil. Semina: Ciências Agrárias, 33(1), 7-18.

Pereira, J. M., Segat, J. C., Baretta, D., Vasconcellos, R. L. F., Baretta, C. R. D. M., \& Cardoso, E. J. B. N. (2017). Soil macrofauna as a soil quality indicator in native and replanted Araucaria angustifolia forests. Revista Brasileira de Ciência do Solo, 4: e0160261.

Pielou, E. C. (1977). Mathematical ecology. John Wiley \& Sons.

Rafael, J. A., Melo, G. A. R., Carvalho, C. J. B., Casari, S. A., \& Constantino, R. (2012). Insetos do Brasil: diversidade e taxonomia. Holos.

Resende, A. S., Campello, E. F. C., Silva, G. T. A., Rodrigues, K. M., Oliveira, W. R. D., \& Correia, M. E. F. (2013). Artropodes do solo durante o processo de decomposição da matéria orgánica. Agronomía Colombiana, 31(1), 89-94.

Ropero, M. C. G., \& Armbrecht, I. (2005). Depredación por hormigas sobre la broca del café Hypothenemus hampei (Curculionidae: Scolytinae) en cafetales cultivados bajo dos niveles de sombra en Colombia. Manejo Integrado de Plagas y Agroecología, Turrialba, 76: 32-40.

Santos, E., Santos, R. C., \& Marques, R. (2015). Macrofauna edáfica na interface solo-serrapilheira e a relação com atributos químicos de um Espodossolo sob dois diferentes sistemas de conservação e uso do solo no município de Paranaguá-PR. Enciclopédia Biosfera: Centro Científico Conhecer, 11(21), $2294-2307$.

Santos, S. R. Q., Vitorino, M. I., Harada, A. Y., Souza, A. M. L., \& Souza, E. B. (2012). A riqueza das formigas relacionada aos períodos sazonais em Caxiuanã durante os anos de 2006 e 2007. Revista Brasileira de Meteorologia, 27(3), 307-314.

Salamon, J., Zaitsev, A., Gartner, S., \& Wolters, V. (2008). Soil macrofaunal response to forest conversion from pure coniferous stands into semi-natural montane forests. Applied Soil Ecology, 40(3), 491-498.

Sales, E. F., Baldi, A., \& Queiroz, R. B. (2018). Fauna edáfica em sistema agroflorestal e em monocultivo de café conilon. Revista Brasileira de Agroecologia, 13(5), 200-209.

Schwinning, S., \& Sala, O. E. (2004). Hierarchy of responses to resource pulses in and semi-arid ecosystems. Oecologia, 141: 211-220.

Shannon, C. E., \& Weaver, W. (1949). The mathematical theory of information. Urbana: University of Illinois Press.

Silva, D. C., Pereira, J. M., Ortiz, D. C., Olivera Filho, L. C. I., Pinto, L. V. A., \& Baretta, D. (2020). Fauna edáfica como indicadora de qualidade do solo em fragmentos florestais e área sob cultivo do cafeeiro. Brazilian Journal of Development, 6(3), 14795-14816.

Silva, G.R., Pauletto, D., \& Silva, A. R. (2020). Dinâmica sazonal de nutrientes e atributos físicos do solo em sistemas agroflorestais. Revista de Ciências Agrárias, 63, 1-9.

Silva, J., Jucksch, I., \& Tavares, R. C. (2012). Invertebrados edáficos em diferentes sistemas de manejo do cafeeiro na Zona da Mata de Minas Gerais. Revista Brasileira de Agroecologia, 7(2), 112-125.

Silva, R. F., Corassa, G. M., Bertollo, G. M., Santi, A. L., \& Steffen, R. B. (2013). Fauna edáfica influenciada pelo uso de culturas e consórcios de cobertura do solo. Revista Agropecuária Tropical, 43(2), 130-137.

Souza, G. S., Dan, M. L., \& Araújo, J. B. S. (2016). Qualidade física do solo sob cafeeiro conilon consorciado e em monocultivo. Coffee Science, 11(2), 180186.

Suzuki, L. E. A. S., Lima, C. L. R, Reinert, D. J., Reichert, J. M., \& Pillon, C. N. (2014). Estrutura e armazenamento de água em um Argissolo sob pastagem cultivada, floresta nativa e povoamento de eucalipto no Rio Grande do Sul. Revista Brasileira de Ciência do Solo, 38(1), 94-106.

Tordoff, G. M., Boddy, L., \& Jones, T. H. (2008). Species-specific impacts of Collembola grazing on fungal foraging ecology. Soil Biology and Biochemistry, $40(2), 434-442$

Tully, K. L., \& Lawrence, D. (2012). Canopy and leaf composition drive patterns of nutrient release from pruning residues in a coffee agroforest. Ecological Applications, 22(4), 1330-1344.

Veiga, J. B., Santos, R. C., Lopes, M. P. M., Silva, R. R., Silva, A. C. S., \& Oliveira, A. S. (2015). Avaliação rápida da riqueza de formigas (Hymenoptera, Formicidae) em fragmentos de floresta ombrófila na região de Alta Floresta, MT. Revista de Ciências Agroambientais, 13(2), 13-18.

Willer, H.; Lernoud, J. (Eds.) (2019). The world of organic agriculture: statistics and emerging trends 2019. Bonn: IFOAM - Organics Internacional, 2019.

Walker, D (1989). Diversity and stability. In: Cherrett, J.M. (Ed). Ecological concepts. Blackwell Scientific Public.

Wezel, A., Soboksa, G., McClelland, S., Delespesse, F., \& Boissau, A. (2015). The blurred boundaries of ecological, sustainable, and agroecological intensification: a review. Agronomy for Sustainable Development, 35: 1283-1295. 